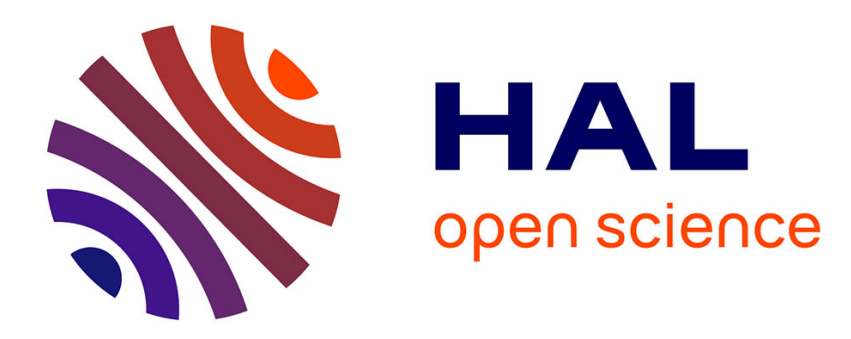

\title{
Analytical TEM study of the oxidation of nickel based superalloys
}

Régine Molins, Eric Andrieu

\section{To cite this version:}

Régine Molins, Eric Andrieu. Analytical TEM study of the oxidation of nickel based superalloys. Journal de Physique IV Proceedings, 1993, 03 (C9), pp.C9-469-C9-475. 10.1051/jp4:1993950 . jpa00252390

\section{HAL Id: jpa-00252390 https://hal.science/jpa-00252390}

Submitted on 1 Jan 1993

HAL is a multi-disciplinary open access archive for the deposit and dissemination of scientific research documents, whether they are published or not. The documents may come from teaching and research institutions in France or abroad, or from public or private research centers.
L'archive ouverte pluridisciplinaire HAL, est destinée au dépôt et à la diffusion de documents scientifiques de niveau recherche, publiés ou non, émanant des établissements d'enseignement et de recherche français ou étrangers, des laboratoires publics ou privés. 


\title{
Analytical TEM study of the oxidation of nickel based superalloys
}

\author{
Régine Molins and Eric Andrieu
}

ENSMP, Centre des Matériaux, BP 87, 91003 Evry Cedex, France

\begin{abstract}
The first stages of oxidation of different nickel based superalloys in air environment at $650^{\circ} \mathrm{C}$ are investigated, using Transmission Electron Microscopy in association with analytical techniques. The alloys differ in microstructure (polycrystal or single crystal, type of hardening precipitates), and chemical analysis (effect of alloying elements). All experiments show evidence of a two oxide layer formation at the surface of the alloy. Different microstructural and chemical changes are demonstrated in the bulk near the metal/oxide interface, leading to a recrystallised band, depleted of hardening precipitates and resulting in a local mechanical softening.
\end{abstract}

\section{Introduction.}

A number of nickel based superalloys are known for being subject to intergranular or interfacial embrittlement due to oxidation. Earlier studies on fatigue crack growth at high temperature clearly demonstrate the influence of oxidation on crack propagation mode. Moreover, the damaging kinetics of the interfaces by oxidation is to be regarded as a major factor when considering high crack growth rates [1-5].

Since the early stages of oxidation determine the damaging process, it is important to characterize the different changes occuring in the material. This preliminary work excludes the mechanical aspects of such phenomena.

At medium temperatures $\left(650^{\circ} \mathrm{C}\right)$, oxidation mechanisms are driven by volume diffusion of elements, as well as interfacial and intergranular diffusion. A fine characterization of diffusion phenomena and an accurate chemical identification of oxidation scale growing at the surface of samples require a high resolution analytical tool.

A TEM, equipped with analytical spectrometers (EDX, EELS), meets these requirements, permitting one to monitor microstructural and chemical changes at a nanometric scale.

Different nickel based superalloys, differing in microstructure (monocrystal, polycrystal, precipitates) and chemical analysis (effect of alloying elements) were investigated after high temperature exposure under air environment.

\section{Materials and experimental.}

Two alloys were considered: first, a monocrystalline alloy. Its $\gamma$ austenitic matrix is reinforced by a $\gamma^{\prime}$ phase, matrix coherent, precipitated as cubes $(500 \mathrm{~nm})$, in a $70 \%$ volume ratio. Its 
chemical composition is the following:

\begin{tabular}{|c|c|c|c|c|c|c|c|c|c|}
\hline Ni & Co & Cr & Mo & W & Al & Ti & Ta & C & Zr \\
\hline Bal & 6,6 & 7,94 & 2,10 & 5,66 & 5,16 & 1,21 & 8,17 & 0,002 & 0,010 \\
\hline
\end{tabular}

The behaviour of the $\gamma / \gamma^{\prime}$ interfaces during oxidation and the microstructure of the oxide scale were examined on this alloy.

Secondly, a polycrystalline alloy, Inconel 718, remarkable for its high $\mathrm{Nb}$ and Fe contents, and structural hardening by $\gamma^{\prime}$ and $\gamma^{\prime \prime}$ intermetallic phases. Its chemical composition is shown below:

\begin{tabular}{|c|c|c|c|c|c|c|c|}
\hline $\mathrm{Ni}$ & $\mathrm{Cr}$ & $\mathrm{Mo}$ & $\mathrm{Fe}$ & $\mathrm{Nb}$ & $\mathrm{Ti}$ & $\mathrm{Al}$ & $\mathrm{C}$ \\
\hline 53,5 & 18,6 & 3,1 & 18,5 & 5 & 0,9 & 0,4 & 0,04 \\
\hline
\end{tabular}

TEM investigation was carried out on a Philips EM430 equipped with a TRACOR energy dispersive X-ray spectrometer. The different phases and oxides have been identified by using electron diffraction techniques and concentration linescans in STEM mode, with a few nanometers probe size.

\section{Results.}

3.1 MONOCRYSTALLINE ALLOY. - In order to emphasize the importance of interfaces, thin foils, electrolytically thinned have been oxidized in air, at $650^{\circ} \mathrm{C}$, for various exposure times ( 30 secondes to 10 minutes). TEM examinations revealed differences in the oxidation mechanisms involved in the matrix, in the intermetallic phases and at the interfaces. After $10 \mathrm{~min}$ exposure (Fig. 1), $\gamma^{\prime}$ precipitates are covered with fine $\mathrm{NiO}$ grains, showing a polycrystalline growth of oxide, with no preferential cristallographic orientation to the substrate. Larger $\mathrm{NiO}$ crystallites $(100 \mathrm{~nm})$ have grown on the $\gamma$ matrix, uniformly oriented in epitaxy as:

$$
\begin{aligned}
& {[001]_{\gamma} / /[001]_{\mathrm{NiO}}} \\
& (001)_{\gamma} / /(001)_{\mathrm{NiO}}
\end{aligned}
$$

The interfaces exhibit a nanocrystalline area, devoid of NiO crystals. EDX analysis of these areas reveal a significant increase of $\mathrm{Cr}$, $\mathrm{Ta}$, $\mathrm{Ti}$ and $\mathrm{Al}$ contents at the interfaces, to the detriment of the matrix and the precipitates, as a complex oxide.

TEM observations of a cross-section specimen after 15 min oxidation in air at $650^{\circ} \mathrm{C}$ (Fig. 2) reveals the presence of two distinct oxide layers on the surface of material. A concentration linescan across these oxides (Fig. 3) and electron diffraction patterns allowed their identification. The outer scale consisted of $(\mathrm{Ni}, \mathrm{Co}) \mathrm{O}$ grains, uniformly oriented. The inner scale was a complex nanocrystalline oxide containing $\mathrm{Cr}$, $\mathrm{Ta}, \mathrm{Ti}$ and $\mathrm{Al}$. We assume that this complex oxide is at the origin of the $\mathrm{CrTaO}_{4}, \mathrm{TiO}_{2}, \mathrm{AlTaO}_{4}$ mixture, reported by some authors for longer oxidation exposure times [6]. No composition gradient is observed in the metal near the interface metal/oxide. 


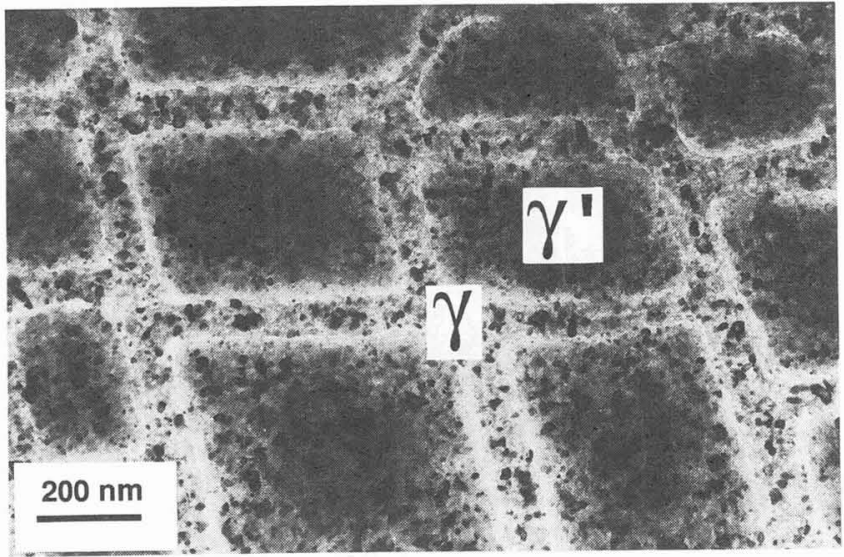

a)

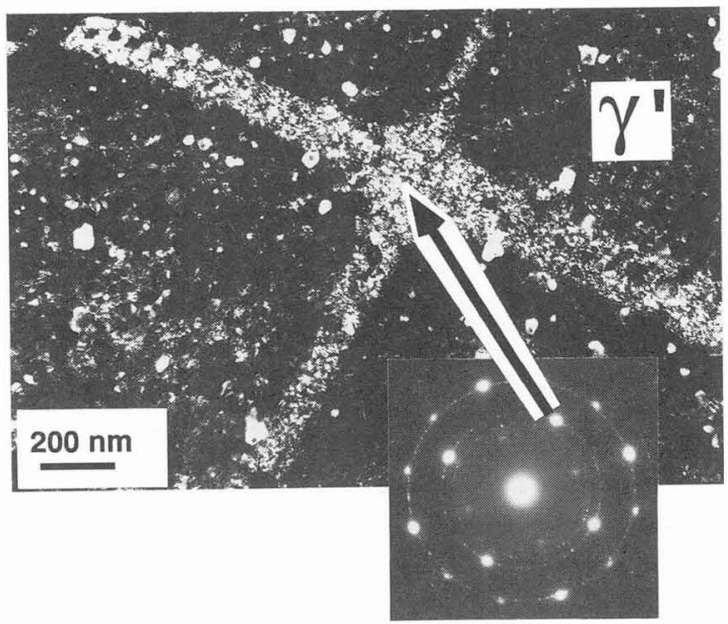

b)

Fig. 1. - a) Bright field and b) dark field and diffraction pattern showing different oxidation mechanisms in the matrix, in the intermetallic phases and at the interfaces.

3.2 INCONEL 718. - TEM examination of cross-section samples oxidized in air $15 \mathrm{~min}$ at $650{ }^{\circ} \mathrm{C}$ (Fig. 4) and concentration linescan (Fig. 5) shows two distinct oxide layers. The outer scale is a NiO type oxide, showing no evidence of the presence of spinels, although containing $\mathrm{Cr}$ and $\mathrm{Fe}$. The inner scale shows a variation in composition from $\mathrm{Cr}_{2} \mathrm{O}_{3}$ near the $\mathrm{NiO}$ interface, to $\mathrm{Cr}(\mathrm{Nb}, \mathrm{Ti}) \mathrm{O}_{4}$ near the alloy.

The concentration linescan shows a depletion of $\mathrm{Cr}, \mathrm{Nb}, \mathrm{Ti}$ and $\mathrm{Al}$ in the matrix near the interface ( $50 \%$ of initial concentrations). A dark field image from a surstructure spot corresponding to $\gamma^{\prime}+\gamma^{\prime \prime}$ indicates a disappearing of these precipitates in the same area (Fig. 6). The future evolution of this area has been checked with a $24 \mathrm{~h}$ oxidation under the same condititions, showing that this free precipitate area eventually results in a small grain size layer (Fig. 7). 


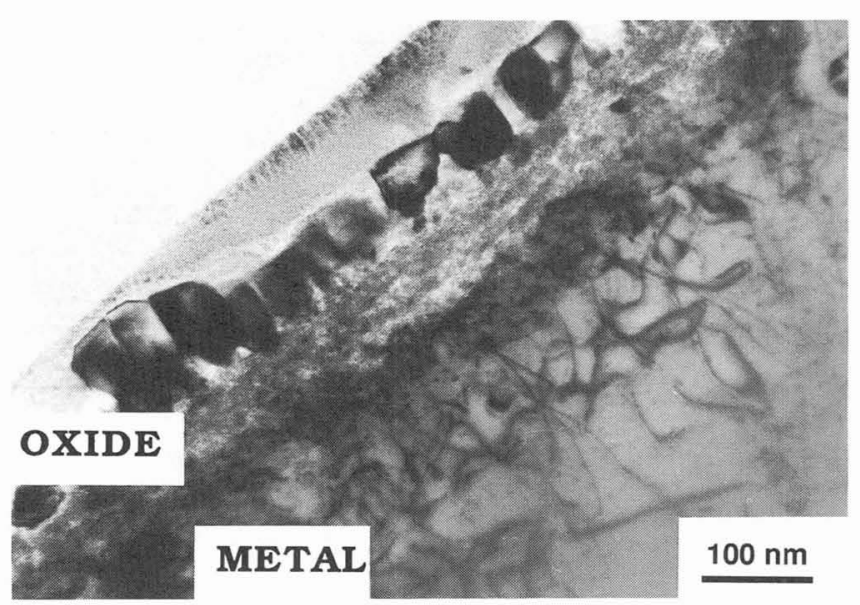

Fig. 2. - Monocrystalline alloy edge-on TEM observation after $15 \mathrm{~min}$ oxidation in air at $650^{\circ} \mathrm{C}$.
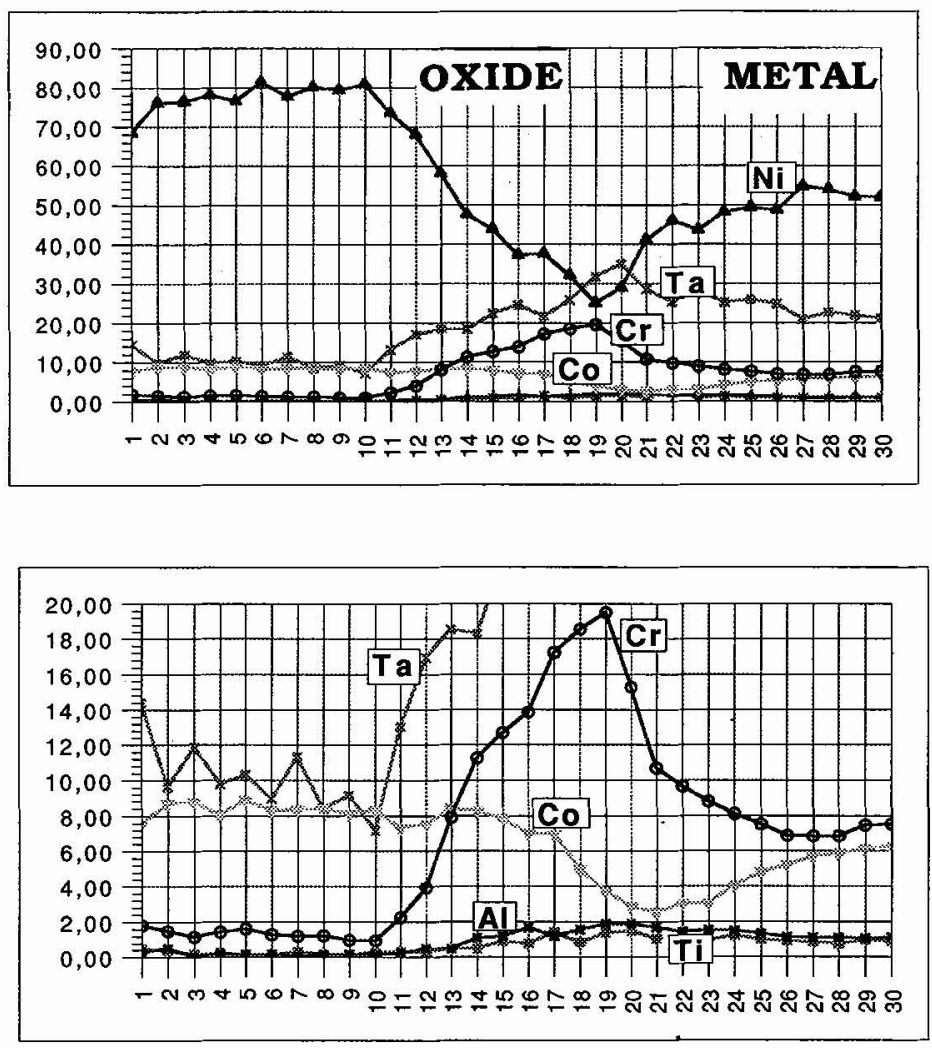

Fig. 3. - STEM elemental concentration linescan through the oxide/alloy interface $(150 \mathrm{~nm})$. 


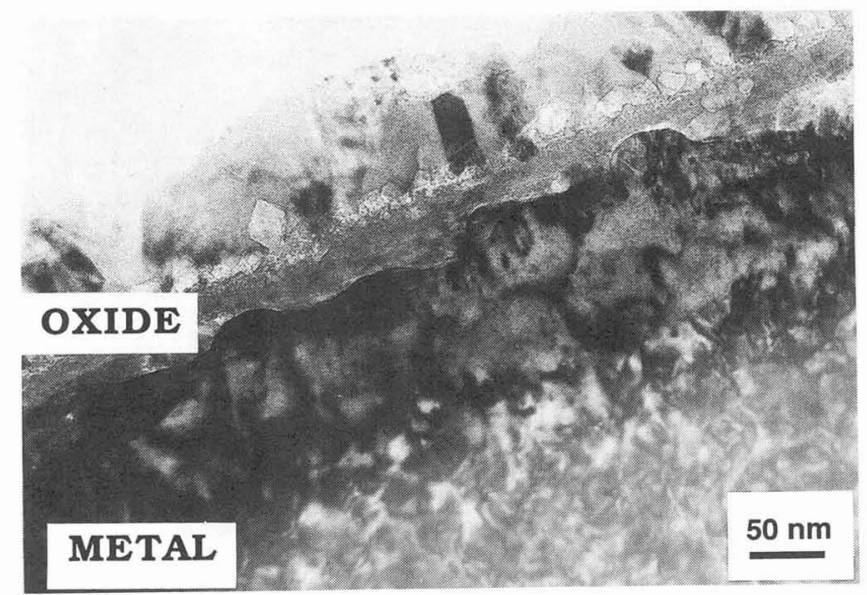

Fig. 4. - TEM edge-on examination of Inconel 718 oxidized in air $15 \mathrm{~min}$ of $650^{\circ} \mathrm{C}$.
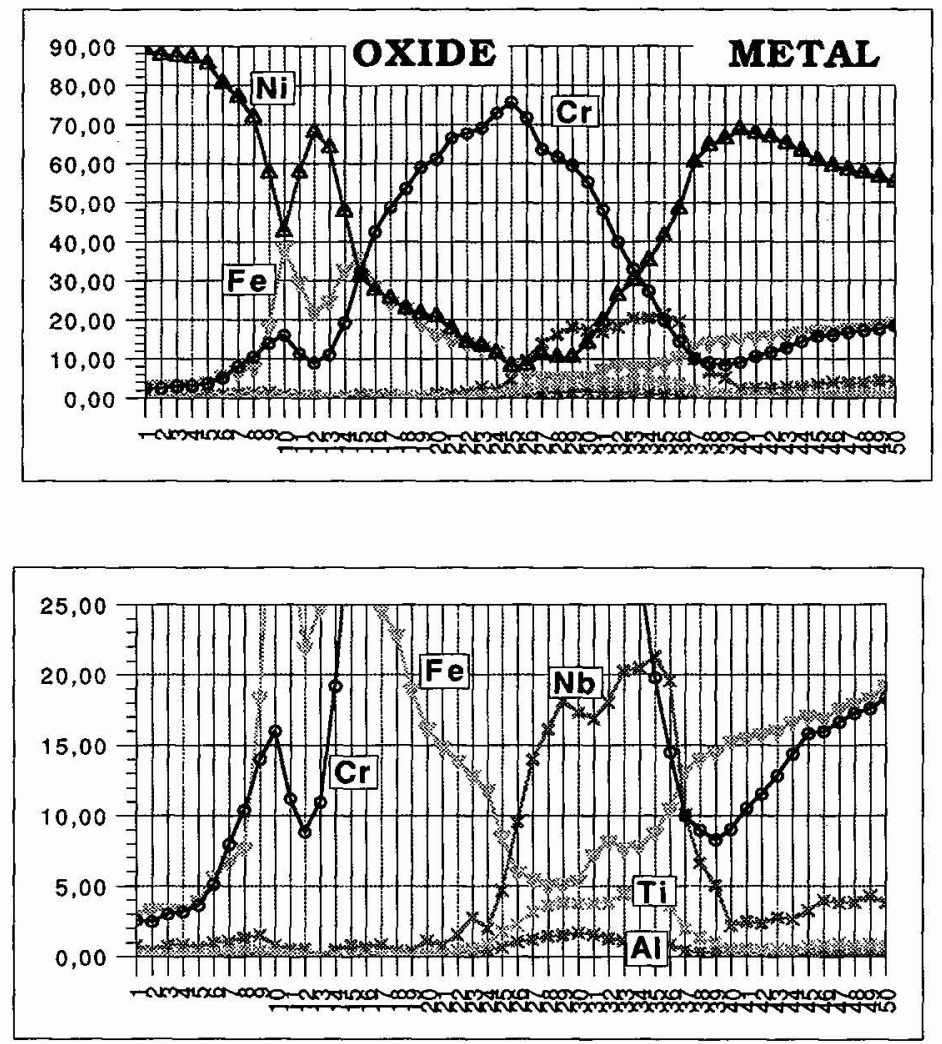

Fig. 5. - STEM elemental concentration linescan through the oxide/alloy interface $(400 \mathrm{~nm})$. 


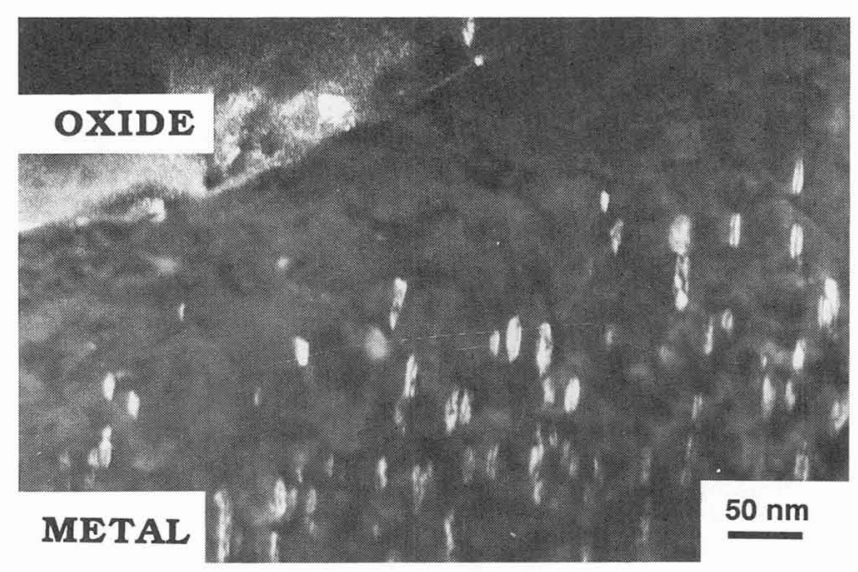

Fig. 6. - Dark field image revealing a $\gamma^{\prime \prime}$ depleted zone.

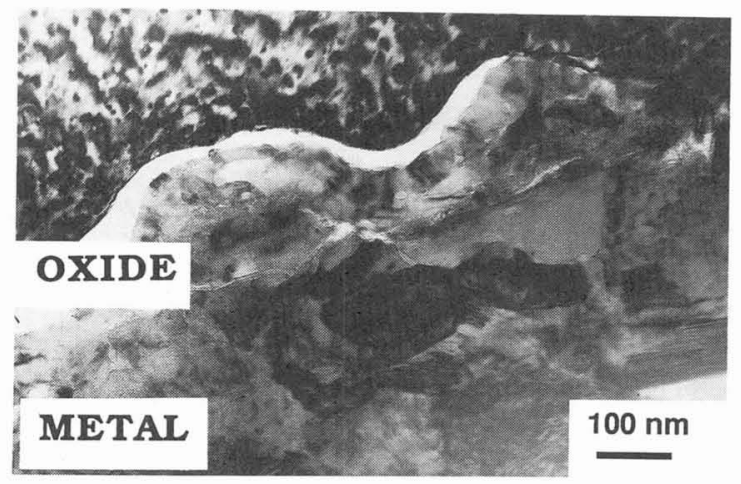

Fig. 7. - Sub grain structure beneath the interface.

\section{Discussion and conclusion.}

The monocrystalline alloy has been included in this study in order to establish a model of oxidation without any participation of grain boundaries. In this respect, further work has to be done on cross-section specimen with shorter exposure time. The first results showed evidence of a double layer oxide scale. The outer scale was $\mathrm{NiO}$. $\mathrm{Al}, \mathrm{Ta}, \mathrm{Ti}$ and $\mathrm{Cr}$ diffuse to the interfaces to form a complex oxide which controls the further oxidation process.

Different microstructural and chemical changes of the Inconel 718 alloy have been demonstrated. In addition to the formation of two distinct oxide layers, a significant depletion of $\mathrm{Cr}$ content near the oxidized surface, together with a rapid disppearance of $\gamma^{\prime}+\gamma^{\prime \prime}$ hardening precipitates is clearly noticeable. The high chromium content of this alloy lowers the solubility of $\mathrm{Al}$ and $\mathrm{Nb}$ in the nickel matrix so that it promotes $\mathrm{Ni}_{3} \mathrm{Al}$ and $\mathrm{Ni}_{3} \mathrm{Nb}$ precipitation. During oxidation, $\mathrm{Cr}$ diffuses to the surface to form $\mathrm{Cr}_{2} \mathrm{O}_{3}$, and thus, the intermetallic phases are solutionized. This phenomenon is already well established for higher temperatures [6, 7].

This structural modification has an obvious influence on the mechanical behaviour of the 
alloy. The existence of a superficial band, with lower $\mathrm{Nb}, \mathrm{Al}$ and $\mathrm{Ti}$ contents leads to a local mechanical softening. The formation and growth of the oxide layer implies short range internal strains. A part of these strains is relaxed by plasticity increasing the dislocation content beneath the oxide. The combination of plasticity and softening causes recrystallization in this modified zone. The number of grain boundaries in this area is increased, enhancing $\mathrm{Cr}$ diffusion and thus provides a better capacity for passivation. Our examination of samples oxidized $15 \mathrm{~min}$ at $650^{\circ} \mathrm{C}$ in air reveal $\mathrm{Cr}$ oxide. This implies that the passivation stage has been reached. This result has also been obtained indirectly using specific fatigue cycle with various hold time at minimum load [8].

The preliminary results of this study show the capability of TEM in association with microanalysis techniques for physico-chemical investigations requiring a nanometric scale resolution. The first stages of oxidation of superalloys result in very thin oxide scales and some chemical variations. Not all the experimental data have been explained, but at least all the phenomena taking place at the interfaces and in the bulk have been described, allowing for an interesting prospect of future results.

\section{References}

[1] FLOREEN S., RAJ R., Flow and fracture at elevated temperatures (ASTM, Ohio, 1983) p. 383.

[2] Ericsson T., Can. Metall. Q. 8 (1987) 177.

[3] Shahinian P., Sadananda K., J. Eng. Mater. Technol. 101 (1979) 244.

[4] PINEAU A., International conference on environment induced cracking of metals, ASM/NACE/AIME (Kohler, Wisconsin, 1988).

[5] Andrieu E., Cozar R., Pineau A., Metallurgy and Applications, Superalloy 718 (Pittsburgh, 1989).

[6] Pieraggi B., Dabosi F., Werkst. Korros. 38 ((1987) 584.

[7] NewCOMB S.B., STOBbS W.M., Microscopy of Oxidation (The Institute of Metals, 1990) p. 135.

[8] Andrieu E., Molins R., Ghonem H., Pineau A., Mater. Sci. Eng. (1992) to be published. 